\title{
The Skin of Van Gogh's Paintings
}

\author{
Joris Dik*, Matthias Alfeld, Koen Janssens and Ella Hendriks \\ * Dept. of Materials Science, Delft University of Technology, Mekelweg 2, 2628CD, Delft, \\ the Netherlands
}

Just microns below their paint surface lay a wealth of information on Old Master

Paintings. Hidden layers can include the underdrawing, the underpainting or

compositional alterations by the artist. In addition, the outer surface of a paint layer may

have suffered from discoloration. Thus, a look through the paint surface provides a look over the artist's shoulder, which is crucial in technical art history, conservation issues and authenticity studies.

In this contribution I will focus on the degradation mechanism of early modern painting pigments used in the work of Vincent van Gogh. These include pigments such as cadmium yellow and lead chromate yellow. Recent studies [1,2,3] of these pigments have revealed stability problems. Cadmium yellow, or cadmium sulfide, may suffer from photo-oxidation at the utmost surface of the paint film, resulting in the formation of colorless cadmium sulfate hydrates. Lead chromate, on the other hand, can be subject to a reduction process, yielding green chrome oxide at the visible surface. Obviously, such effects can seriously disfigure the original appearance of Van Gogh's oeuvre, as will be shown by a number of case studies.

The degradation mechanisms were revealed using an elaborate analytical campaign, mostly involving cross-sections from the original artwork, as well as model paintings that had been aged artificially. First, we used laboratory-based techniques, including optical and electron microscopy. Second, we turned to synchrotron-based $\mathrm{x}$-ray microscopy. Using $\mu$-XRF, $\mu$-XRD and $\mu$-XANES we were able to characterize our samples elementally and structurally at the micrometer scale.

References:

[1] Letizia Monico, Geert Van der Snickt, Koen Janssens, Wout De Nolf, Costanza Miliani, Johan Verbeeck, He Tian, Haiyan Tan, Joris Dik, Marie Radepont, and Marine Cotte, "Degradation Process of Lead Chromate in Paintings by Vincent van Gogh Studied by Means of Synchrotron X-raySpectromicroscopy and Related Methods. 1. Artificially Aged Model Samples", Analytical Chemistry, 83 (2011) 1214-1224, doi 10.1021/ac102424h

[2] Letizia Monico, Geert Van der Snickt, Koen Janssens, Wout De Nolf, Costanza Miliani, Marie Radepont, Ella Hendriks, Muriel Geldof, and Marine Cotte, "Degradation Process of Lead Chromate in Paintings by Vincent van Gogh Studied by Means of Synchrotron X-raySpectromicroscopy and Related Methods. 2. Original Paint Layer Samples", Analytical Chemistry, 83 (2011) 1224-1231, doi 10.1021/ac1025122

[3] G. van der Snickt, J. Dik, K. Janssens, J. Jaroszewicz, W. De Nolf, L. van der Loef, J. Groenewegen, and M. Cotte, Characterisation of a degraded Cadmium Yellow (CdS) Pigment in Oil Paintings by Means of Synchrotron Light based X-Ray Techniques: SR $\mu$-XRF, SR $\mu$-XANES and SR $\mu$-XRD, Analytical Chemistry, vol. 81, 2009, p. 2600-2610 


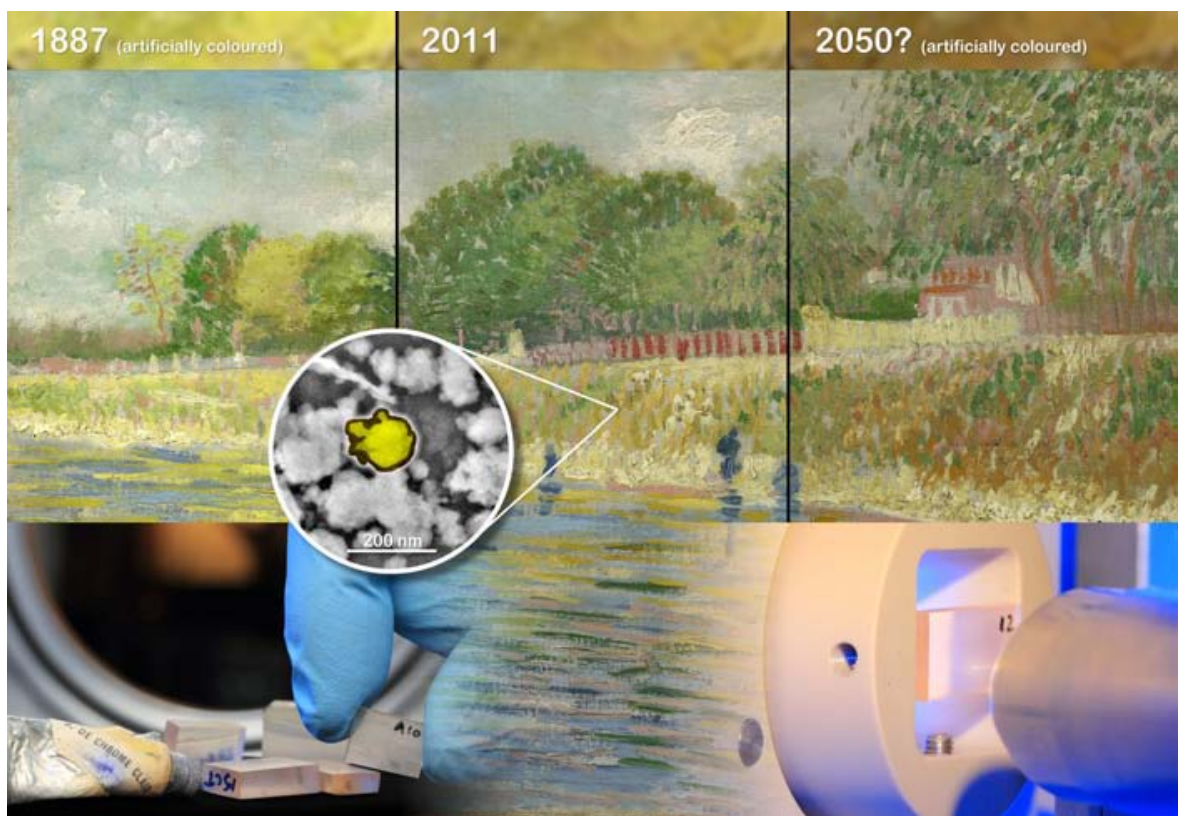

'Bank of the Seine' (V. Van Gogh, 1887), divided in three and artificially colored to simulate a possible original, current and future appearance. Credit: ESRF/Antwerp University/Van Gogh Museum 